\title{
Antimicrobial Compounds in the Volatilome of Social Spider Communities
}

\author{
Alexander Lammers ${ }^{1,2 *}$, Hans Zweers², Tobias Sandfeld ${ }^{3}$, Trine Bilde4, Paolina Garbeva², \\ Andreas Schramm ${ }^{3}$ and Michael Lalk ${ }^{1 *}$ \\ 'Department of Cellular Biochemistry and Metabolomics, University of Greifswald, Greifswald, Germany, ${ }^{2}$ Department \\ of Microbial Ecology, Netherlands Institute of Ecology (NIOO-KNAW), Wageningen, Netherlands, ${ }^{3}$ Section for Microbiology, \\ Department of Biology, Aarhus University, Aarhus, Denmark, ${ }^{4}$ Section for Genetics, Ecology and Evolution, Department \\ of Biology, Aarhus University, Aarhus, Denmark
}

OPEN ACCESS

Edited by:

Eoin L. Brodie,

Lawrence Berkeley National Laboratory, United States

Reviewed by: Hongjie Li,

Ningbo University, China Martin Kaltenpoth,

Max Planck Institute for Chemical

Ecology, Germany

Michael Poulsen,

University of Copenhagen, Denmark Nanna Vidkjær,

University of Copenhagen, Denmark, in collaboration with reviewer MP

*Correspondence:

Alexander Lammers alexander.lammers@uni-greifswald.de Michael Lalk

lalk@uni-greifswald.de

Specialty section: This article was submitted to

Terrestrial Microbiology, a section of the journal

Frontiers in Microbiology

Received: 26 April 2021

Accepted: 31 July 2021

Published: 24 August 2021

Citation:

Lammers A, Zweers $H$, Sandfeld T, Bilde T, Garbeva P,

Schramm A and Lalk M (2021)

Antimicrobial Compounds in the Volatilome of Social Spider

Communities.

Front. Microbiol. 12:700693 doi: 10.3389/fmicb.2021.700693
Social arthropods such as termites, ants, and bees are among others the most successful animal groups on earth. However, social arthropods face an elevated risk of infections due to the dense colony structure, which facilitates pathogen transmission. An interesting hypothesis is that social arthropods are protected by chemical compounds produced by the arthropods themselves, microbial symbionts, or plants they associate with. Stegodyphus dumicola is an African social spider species, inhabiting communal silk nests. Because of the complex three-dimensional structure of the spider nest antimicrobial volatile organic compounds (VOCs) are a promising protection against pathogens, because of their ability to diffuse through air-filled pores. We analyzed the volatilomes of $S$. dumicola, their nests, and capture webs in three locations in Namibia and assessed their antimicrobial potential. Volatilomes were collected using polydimethylsiloxane (PDMS) tubes and analyzed using GC/Q-TOF. We showed the presence of 199 VOCs and tentatively identified 53 VOCs. More than $40 \%$ of the tentatively identified VOCs are known for their antimicrobial activity. Here, six VOCs were confirmed by analyzing pure compounds namely acetophenone, 1,3-benzothiazole, 1decanal, 2-decanone, 1-tetradecene, and docosane and for five of these compounds the antimicrobial activity were proven. The nest and web volatilomes had many VOCs in common, whereas the spider volatilomes were more differentiated. Clear differences were identified between the volatilomes from the different sampling sites which is likely justified by differences in the microbiomes of the spiders and nests, the plants, and the different climatic conditions. The results indicate the potential relevance of the volatilomes for the ecological success of $S$. dumicola.

Keywords: volatile organic compound, chemical ecology, antimicrobial, Stegodyphus dumicola, social arthropods

\section{INTRODUCTION}

Organisms use chemicals to exchange information, coordinate their behavior, or protect themselves against pathogens (Chen et al., 1998; Rowan, 2011; Schulz-Bohm et al., 2017). For example, social arthropods depend on chemical compounds, which are vital for communication and other functions mediating a high level of organization. They are able to inhabit extreme environments, 
use numerous resources, and finally often outcompete other arthropods (Wilson, 1987; Hölldobler and Wilson, 1990; Fisher et al., 2019). However, a fundamental problem of social arthropods is the elevated risk of acquiring and transmitting pathogens, as their dense colony associations increase the risk of infections and pathogen transmission (Bratburd et al., 2020). The risk of infections has led to a number of adaptations ranging from behaviors that reduce the risk of transmission (Müller and Schmid-Hempel, 1993) to the use of antimicrobial compounds. Antimicrobial compounds can be produced among others by the arthropod hosts themselves (Graystock and Hughes, 2011), symbiotic microorganisms (Musa Bandowe et al., 2009), or surrounding plants (Tariq et al., 2019).

Sociality has also evolved within the class of arachnids (Lubin and Bilde, 2007). Stegodyphus dumicola is a social spider species living in large groups in southern and central Africa (Aviles, 1997; Lubin and Bilde, 2007). These spiders build communal nests where reproduction takes place and which protects the spiders against heat/dehydration, UV-radiation, and predators (Supplementary Figure 1A; Seibt and Wickler, 1990; Henschel, 1998; Lubin and Bilde, 2007). The nest is surrounded by three-dimensional capture webs used for communal prey capture (Majer et al., 2018). The social lifestyle in spiders comes with elimination of pre-mating dispersal and therefore a strictly inbreeding mating system. Combined with frequent extinction and colonization events, this results in extremely low genetic diversity (Lubin and Bilde, 2007; Settepani et al., 2014, 2016, 2017). Homozygosity in genes within individuals, and low population genetic diversity in for example immune genes is likely to be associated with elevated vulnerability to infections. This substantiates the hypothesis that antimicrobial compounds play an important role in protecting the spider hosts against pathogens.

Due to the complex nest structure, including tightly woven silk structures with multiple narrow tunnels and chambers, volatile organic compounds (VOCs) have a possible importance in pathogen defense. VOCs are carbon-based compounds with molecular masses below $400 \mathrm{Da}$, high vapor pressures, low boiling points, and lipophilic moiety, properties that imply versatility of these compounds in all terrestrial ecosystems (Rowan, 2011; Schmidt et al., 2015b; Tyc et al., 2015). As opposed to soluble compounds, VOCs can diffuse through air-filled pores in complex ecosystems such as soil and hence do not depend on solvents (Schmidt et al., 2015a). That suggests that VOCs have the potential to reach all the internal surfaces of the spider nest and serve as inhibitors of pathogens from a distance. Antimicrobial VOCs are widely produced by microorganisms, plants, and animals: For example, bacteria isolated from the rhizosphere are known for producing VOCs with antimicrobial properties that can have protective functions for symbiotic plants (Tyc et al., 2015; Ossowicki et al., 2017). Plants use VOCs by themselves in various functions such as preventing microbial infections (Hammerbacher et al., 2019). In termites, volatile pheromones produced by queens, primarily used for communication, were shown to also have antifungal effects, indicating a role in pathogen defense (Matsuura and Matsunaga, 2015). Red fire ants and beetles are also known to use VOCs with antimicrobial properties (Gross et al., 2008; Wang et al., 2015). Here, we propose that VOCs may have a protective antimicrobial function in the nest system of the social spider S. dumicola.

The aim of this study is to describe the volatilomes of the spider S. dumicola and its nest and web, respectively, and to assess its potential antimicrobial effects. We hypothesized the presence of antimicrobial VOCs in the volatilomes of $S$. dumicola, its nest, and catching web. Next, we investigated whether the spider, the nest, and the capture web emit different VOC blends. Finally, we investigated volatilomes collected at different geographical locations to assess differences between the VOC blends. For this, we analyzed and compared the volatilomes from spider nests, catching webs, and the spiders themselves at three sampling sites in a north-south gradient in Namibia. Furthermore, we tested a selection of identified VOCs as pure compounds for their antimicrobial activity against microbial pathogens of spiders and humans.

\section{MATERIALS AND METHODS}

\section{Sampling Sites}

The volatilome samples were taken at three different sampling sites in Namibia between 8th-26th February, 2019 (Supplementary Figure 2). The locations were close to the Etosha National Park ("Otavi”; S19.47, E17.19), the capital ("Windhoek"; S22.57, E17.21), and a small town ("Stampriet"; S23.74, E18.19). Otavi and Stampriet are at an altitude of $\sim 1,300 \mathrm{~m}$ and Windhoek of $\sim 2,000 \mathrm{~m}$. At each sampling site five nests were analyzed and defined as biological replicates. The maximal distance between the used spider nests were $150 \mathrm{~m}$ in Otavi, $300 \mathrm{~m}$ in Windhoek, and 1,200 $\mathrm{m}$ in Stampriet (Supplementary Figure 2 inserts). Otavi is a humid sampling site in the North, Windhoek is mountainous, and Stampriet is because of its closeness to the Kalahari Desert on average the warmest region.

In Otavi the nests were located in plants of the species Combretum imberbe, Acacia mellifera, Ziziphus mucronata, and Grewia flava; in Windhoek in Acacia hereroensis, Acacia mellifera, and Acacia hebeclada; in Stampriet in Acacia nebrownii. We empirically observed the highest density of plants in Otavi and lowest in Stampriet.

The humidity and temperature data during the volatilome trapping were measured using iButton ${ }^{\circledR}$ logger every $300 \mathrm{~s}$ (Type DS1923, Maxim Integrated, San Jose, California, United States). The temperature and humidity data inside the nests during the VOC samplings revealed the nests in Otavi as warmest and less humid and the nests in Windhoek as less warm and most humid (Supplementary Figure 3).

\section{Volatilome Trapping}

Polydimethylsiloxane (PDMS) tubes (internal diameter $1 \mathrm{~mm}$, external diameter $1.8 \mathrm{~mm}$, Carl Roth, Karlsruhe, Germany) were cut into $5 \mathrm{~mm}$ pieces and threaded on needles. The tubes were fully covered with acetonitrile/methanol (4/1, v/v) and incubated for $3 \mathrm{~h}$ at room temperature. Subsequently they were dried under $\mathrm{N}_{2}$ flow $(5 \mathrm{l} / \mathrm{min})$ and heated up to $210^{\circ} \mathrm{C}$ for $1.5 \mathrm{~h}$ under He flow 
(5 1/min). Glass vials for storing the tubes until usage and needles for fixation at the spider nests and webs were cleaned similarly.

The PDMS tubes were used to trap volatile organic compounds (VOCs) from the spider nests, catching webs, and isolated living spiders. For trapping VOCs from the nests, five tubes were fixed with needles at the nest surfaces (Supplementary Figure 1B). For trapping VOCs from the catching webs, five PDMS tubes were threaded on needles to increase the surface and stuck to the catching webs in an approximately $30 \mathrm{~cm}$ diameter around the nests. PDMS tubes in sterile, open Petri dishes in $1 \mathrm{~m}$ distance to the nests were used as controls. The nests and webs were irritated as little as possible before, during, and after VOC trapping to stress the spiders as little as possible. No spiders or material were removed before trapping. VOCs from spiders were trapped by keeping five spiders from each nest together with five PDMS tubes in a sterile Petri dish. The controls for spider VOCs were closed Petri dishes with five PDMS tubes. All PDMS tubes were left for $30 \mathrm{~min}$ and immediately stored in closed glass vials at $-20^{\circ} \mathrm{C}$ until VOC analysis. One nest (together with its catching web and spiders) was defined as one replicate. Per sampling site 3-5 replicates were taken.

\section{GC/Q-TOF Analysis}

The VOCs were released from the PDMS tubes using an automated thermodesorption unit (Unity TD-100, Markes International, Llantrisant, United Kingdom) at $280^{\circ} \mathrm{C}$ for $8 \mathrm{~min}$ with a $\mathrm{He}$ flow of $50 \mathrm{ml} / \mathrm{min}$. The VOCs got cold trapped at $-10^{\circ} \mathrm{C}$ on a Tenax trap (Markes International, Llantrisant, United Kingdom) and released at $300^{\circ} \mathrm{C}$ within $10 \mathrm{~min}$. A split ratio of $1 / 4$ was used. The VOCs were transferred $\left(195^{\circ} \mathrm{C}\right.$ transfer line) to the Agilent $7890 \mathrm{~B}$ GC (Agilent Technologies, Inc., Santa Clara, CA, United States) with an DB-5 ms ultra inert column (30 m length, $0.25 \mathrm{~mm}$ internal diameter, $0.25 \mu \mathrm{m}$ film thickness, 122-5,532, Agilent Technologies, Inc., Santa Clara, CA, United States) and a run time of $35.6 \mathrm{~min}$. The temperature program was set to $39^{\circ} \mathrm{C}$ for $1 \mathrm{~min}$ followed by heating up to $315^{\circ} \mathrm{C}$ with $10^{\circ} \mathrm{C} / \mathrm{min}$ and holding for $7 \mathrm{~min}$. The MS $\left(280^{\circ} \mathrm{C}\right.$ transfer line) was performed with Agilent $7200 \mathrm{AB}$ Q-TOF at $70 \mathrm{eV}$ in electron ionization mode with a source temperature of $230^{\circ} \mathrm{C}$. Mass spectra were recorded in full-scan-mode $(\mathrm{m} / \mathrm{z}$ 30-400, 4 scans/s, $2 \mathrm{GHz}$ Extended Dynamic Range).

For calibration of the retention index $1 \mu \mathrm{l}$ alkane standard solution of $\mathrm{C}_{8}-\mathrm{C}_{20}$ (40 mg/l in Hexane; 04070-5ML; Merck, Darmstadt, Germany) was spiked on an empty Tenax trap and measured as described above. The presence of acetophenone, 2-decanone, 1-decanal, 1,3-benzothiazole, 1-tetradecene, and docosane ( $1 \mu \mathrm{g} / \mathrm{ml}$ in $\mathrm{MeOH}$; all purchased by Merck, Darmstadt, Germany) in the volatilomes was confirmed by measuring pure standard compounds on the same way.

\section{GC/Q-TOF Data Processing}

For GC/Q-TOF data processing the raw data were exported as content definition file (CDF) and imported into MZmine (Version 2.20; ${ }^{\odot}$ Copyright 2015; Pluskal et al., 2010). Mass detection, chromatogram building, deconvolution (local minimum algorithm), and peak alignment (RANSAC, random sample consensus) were performed using MZmine (for detailed parameters are provided in Supplementary Table 1). The peak lists were exported as comma-separated values (CSV) files. The files were uploaded to MetaboAnalyst (Version 4.0, Xia Lab, Montreal, Canada; Xia and Wishart, 2011), filtered (interquartile range), transformed (log transformation), and scaled (auto) before statistical tests were performed. Statistically significant differences between the samples and controls were identified by analysis of variance (ANOVA) followed by Fisher's least significant difference (LSD). Furthermore, a mass feature must be found in at least 4 of 5 or 3 of 4 of the biological replicates to get valued as such.

Compound identification was performed using AMDIS 2.72 (National Institute of Standards and Technology, United States) based on retention index comparison and mass spectrum comparison to three libraries providing more than 1.4 million spectra namely NIST 2014 V2.20 (National Institute of Standards and Technology, Gaithersburg, Maryland, United States), Wiley 7th edition spectral libraries (Wiley, Hoboken, New Jersey, United States), and an internal library of NIOO-KNAW (Netherlands Institute of Ecology, Wageningen, The Netherlands). The retention index tolerance was \pm 10 and the minimum mass spectrum match was $600 \%$. If a mass feature complied both criteria, a visual comparison of the mass spectra was performed, and designated as "tentatively identified." Additionally, the retention indices and mass spectra of the "identified" compounds were compared to pure standard compounds measured in the same GC/Q-TOF system. Unknown mass features were assumed as different ones when the retention indices differed by $>6$.

\section{Antimicrobial Test of Pure VOCs}

Five VOCs identified using pure standard compounds, namely acetophenone, 2-decanone, 1-decanal, 1,3-benzothiazole, and 1-tetradecene, were tested as pure compounds for their antimicrobial activity. The compounds were selected based on literature indicating their high antimicrobial activity (Supplementary Table 2). We used Bacillus thuringiensis (DSM 2046), Staphylococcus aureus (DSM 799), Escherichia coli (DSM 787), and Candida albicans (DSM 10697) as test strains to cover all, a suggested spider pathogen, Gram positive and negative bacteria, as well as a yeast. The latter three strains are common human pathogens and were chosen as model organisms. All strains were bought at the German Collection of Microorganisms and Cell Cultures (DSMZ, Braunschweig, Germany). Before use the strains were precultured overnight at $37^{\circ} \mathrm{C}$ on Mueller Hinton Agar II $(2.0 \mathrm{~g} / \mathrm{l}$ beef heart infusion, $17.5 \mathrm{~g} / \mathrm{l}$ acid casein hydrolysate, $1.5 \mathrm{~g} / \mathrm{l}$ starch, $17.0 \mathrm{~g} / \mathrm{l}$ agar; Becton Dickinson, Franklin Lakes, New Jersey, United States).

The test strains were diluted to an $\mathrm{OD}_{600}$ of 0.1 in Mueller Hinton Broth II (17.5 g/l casein acid hydrolysate, $3 \mathrm{~g} / \mathrm{l}$ beef extract, $1.5 \mathrm{~g} / \mathrm{l}$ starch; Sigma-Aldrich, St. Louis, Missouri, United States). $10 \mathrm{ml}$ of the prepared cell solution was transferred into a $100 \mathrm{ml}$-Erlenmeyer flask and test compounds, were added at a final concentration of $30 \mathrm{mM}$. The flasks were 
sealed immediately with aluminum foil and wrapping film and incubated $\left(37^{\circ} \mathrm{C}, 150 \mathrm{rpm}\right)$. After $24 \mathrm{~h}$ the $\mathrm{OD}_{600}$ was measured and compared to the negative control without added compounds ( $t$-test, $p \leq 0.05)$. Three biological replicates for each test strain in combination with each test compound were performed.

Additionally, an agar diffusion test was performed based on the protocol of Hudzicki (2009). The test strains were diluted to an $\mathrm{OD}_{600}$ of 0.125 in $\mathrm{NaCl}(0.9 \%)$ and spread on Mueller Hinton II agar plates (Becton Dickinson, Fraklin Lakes, New Jersey, United States) using cotton swabs. Five microliters of the pure compounds were pipetted on empty cotton disks (6 $\mathrm{mm}$ diameter) and placed on the plates before sealing with Parafilm ${ }^{\circledR}$. Empty cotton disks were used as negative controls. For positive controls cotton disks with gentamicin (SensiDisk $^{\mathrm{TM}}$, $10 \mathrm{U}$, Becton Dickinson, Franklin Lakes, New Jersey, United States) were used for bacterial strains and amphotericin B (ROTI ${ }^{\circledR}$ Antibiotic Disks, 100 U, Carl Roth, Karlsruhe, Germany) for the yeast. After incubation $\left(24 \mathrm{~h}, 37^{\circ} \mathrm{C}\right)$ the zones of inhibition (ZOI) were measured.

\section{Identification of Differences Between Volatilomes}

To compare the volatilomes between the nests, catching webs, and spiders, and between the sampling sites, partial least squares discriminant analysis (PLS-DA) plots and Euler plots were made. PLS-DA plots were based on all mass features (including relative intensities) and made using MetaboAnalyst (Version 4.0, Xia Lab, Montreal, Canada; Xia and Wishart, 2011). Euler plots were made based on all compounds (Supplementary Table 2) VOCs using RStudio (RStudio, Inc., Version 1.2.5033).

\section{RESULTS}

\section{Antimicrobial VOCs in the Stegodyphus dumicola Volatilome}

The analyses of the volatilomes of all sampling sites resulted in the tentative identification of 53 compounds ranging from $\mathrm{C}_{4}$ up to $\mathrm{C}_{24}$ (Table 1 and Supplementary Table 2). Most of the identified VOCs were pure hydrocarbons (41\%) or contained oxygen (51\%). Eight percent of compounds contained nitrogen, sulfur, or halogens. The VOCs belonged to various chemical classes. Most common were alkanes, carboxylic acids, alcohols, benzenes, ketones, alkenes, aldehydes, and terpenoids. One hundred forty-six compounds could not be tentatively identified by mass spectra comparison with databases and are therefore listed as unknown (Supplementary Table 2). Antimicrobial activity was assigned to 21 of the 53 tentatively identified VOCs (Table 1) based on published data for the pure compounds or mixtures such as essential oils containing the compound (references in Supplementary Table 2). Most of those compounds are known for both antibacterial and antifungal activities. By analyzing pure standard compounds, we confirmed the presence of acetophenone, 2-decanone, 1-decanal, 1,3-benzothiazole, 1-tetradecene, and docosane (Supplementary Figure 4).

\section{Effect of Antimicrobial VOCs on Pathogens}

A selection of pure compounds found exclusively in the nest volatilome (acetophenone and 2-decanone), the nest and web volatilome (1-decanal and 1,3-benzothiazole) and in the spider volatilome (1-tetratdecene) were tested for their antimicrobial activities against a spectrum of microbial pathogens. All five tested compounds displayed antimicrobial activity (Figure 1). Acetophenone, 2-decanone, and 1,3benzothiaziole significantly inhibited all four tested pathogens. 1 -Tetradecene and 1-decanal significantly inhibited only three pathogens, namely B. thuringiensis, S. aureus, and C. albicans but not E. coli. 1-Decanal even increased the growth of $E$. coli albeit not significantly. The spider pathogen $B$. thuringiensis was significantly inhibited by all five compounds. Additionally, we tested the antimicrobial activity of the compounds using an agar diffusion test resulting in similar inhibitions (Supplementary Figure 5).

\section{Comparison of Nest, Web, and Spider Volatilomes}

At all sampling sites, more VOCs were detected in the nest and web samples as compared to the spider samples (Figure 2 and Supplementary Figure 6). The nest and web volatilomes from the site Otavi shared many common VOCs (63 in total, Figure 2A). Only eight unknown VOCs were commonly found in the nest, web, and spider volatilomes. In Windhoek we found nearly twice the number of VOCs in the nest compared to the web and spider volatilomes (Figure 2B). Two unknown VOCs were common and detected in the nest, web, and spider volatilomes. In Stampriet, similar to Otavi, the nest and web shared a high number of VOCs (Figure 2C). Only one compound was found in the combined volatilome of nest, web, and spider and identified as oxymethylencampher.

\section{Comparison of Volatilomes From Different Climatic Regions}

Analyzing the volatilomes of the three sampling sites using PLSDA indicated that the nest volatilomes from the three sampling sites clearly differed from each other, with the largest differences being observed between Otavi and Windhoek (Figure 3). The confidence regions of Otavi and Stampriet showed only small overlays (Figure 3A). The web volatilomes separated in a similar way with a small overlayed area between Stampriet and Windhoek (Figure 3B). The confidence regions of the spider VOCs of Stampriet overlayed in large parts with those of Windhoek, whereas the Otavi volatilome was clearly separated from the other regions (Figure 3C).

The Euler-plots based on all identified and unknown VOCs indicated that the Otavi volatilomes show the highest number of VOCs in the nest, and web volatilomes, followed by Stampriet, and Windhoek (Figure 4 and Supplementary Figure 6). The spider volatilomes contained the highest number of VOCs in Otavi and the lowest in Stampriet. The nest volatilomes of the three sampling sites shared 12 common VOCs, and the web 11 common VOCs. The spider volatilomes did not contain common 
TABLE 1 | List of identified compounds in the nest (N), web (W), and spider (S) volatilomes of the different sampling sites Otavi, Windhoek, and Stampriet with known antimicrobial activity.

\begin{tabular}{|c|c|c|c|c|c|c|c|c|c|c|c|c|c|}
\hline \multirow[b]{2}{*}{ Compound } & \multirow[b]{2}{*}{ Class } & \multirow[b]{2}{*}{$\begin{array}{l}\text { Molecular } \\
\text { Formular }\end{array}$} & \multirow[b]{2}{*}{$\begin{array}{l}\text { Antimicrobial } \\
\text { Activity }\end{array}$} & \multirow[b]{2}{*}{$\begin{array}{l}\text { Compound } \\
\text { Origin }\end{array}$} & \multicolumn{3}{|c|}{ Otavi } & \multicolumn{3}{|c|}{ Windhoek } & \multicolumn{3}{|c|}{ Stampriet } \\
\hline & & & & & $\mathbf{N}$ & $\mathbf{w}$ & $\mathbf{S}$ & $\mathbf{N}$ & $\mathbf{W}$ & S & $\mathbf{N}$ & $\mathbf{W}$ & $\mathbf{S}$ \\
\hline 1-Heptanal & Aldehyde & $\mathrm{C}_{7} \mathrm{H}_{14} \mathrm{O}$ & $b, f$ & $\mathrm{p}$ & & & & & & $\times$ & & & \\
\hline 2-Ethylhexanol & Alcohol & $\mathrm{C}_{8} \mathrm{H}_{18} \mathrm{O}$ & $b, f$ & $p, f$ & & & & $\times$ & $\times$ & & $\times$ & $\times$ & \\
\hline Acetophenone & Ketone & $\mathrm{C}_{8} \mathrm{H}_{8} \mathrm{O}$ & $b$ & $?$ & $\times$ & & & $\times$ & & & & & \\
\hline 1-Non-anal & Aldehyde & $\mathrm{C}_{9} \mathrm{H}_{18} \mathrm{O}$ & $b, f$ & $\mathrm{p}$ & $\times$ & & & & & & $\times$ & & \\
\hline Levomenthol & Alcohol & $\mathrm{C}_{10} \mathrm{H}_{20} \mathrm{O}$ & $b, f$ & $\mathrm{p}$ & & $\times$ & & & & & & & \\
\hline 2-Decanone & Ketone & $\mathrm{C}_{10} \mathrm{H}_{20} \mathrm{O}$ & $b, f$ & $p, b$ & & & & $\times$ & & & $\times$ & & \\
\hline Dodecane & Alkane & $\mathrm{C}_{12} \mathrm{H}_{26}$ & $b, f$ & $p, b$ & & & & & & & $\times$ & & \\
\hline 1-Decanal & Aldehyde & $\mathrm{C}_{10} \mathrm{H}_{20} \mathrm{O}$ & $b, f$ & $\mathrm{p}$ & $\times$ & $\times$ & & & & & & & \\
\hline 1,3-Benzothiazole & Benzothiazole & $\mathrm{C}_{7} \mathrm{H}_{5} \mathrm{NS}$ & $b, f$ & $\mathrm{p}$ & $\times$ & $\times$ & & $\times$ & & & & & \\
\hline 1-Undecanol & Alcohol & $\mathrm{C}_{11} \mathrm{H}_{24} \mathrm{O}$ & $\mathrm{b}$ & $?$ & & & & & & & & $\times$ & \\
\hline 1-Dodecene & Alkene & $\mathrm{C}_{12} \mathrm{H}_{24}$ & $\mathrm{~b}$ & $\mathrm{p}$ & & & & & & & $\times$ & & \\
\hline 1-Tridecene & Alkene & $\mathrm{C}_{13} \mathrm{H}_{26}$ & $b$ & $\mathrm{p}, \mathrm{a}$ & $\times$ & $\times$ & & $\times$ & $\times$ & & $\times$ & & \\
\hline $\begin{array}{l}\text { 2-Ethyl-3-hydroxyhexyl } \\
\text { 2-methylpropanoate }\end{array}$ & Carboxylic Acid & $\mathrm{C}_{12} \mathrm{H}_{24} \mathrm{O}_{3}$ & $b, f$ & $\mathrm{p}$ & $\times$ & & & & & & & & \\
\hline 1-Tetradecene & Alkene & $\mathrm{C}_{14} \mathrm{H}_{28}$ & $b, f$ & $p, f$ & & & $\times$ & & & & & & \\
\hline 1-Dodecanal & Aldehyde & $\mathrm{C}_{12} \mathrm{H}_{24} \mathrm{O}$ & $b, f$ & $\mathrm{p}$ & & & & & & & $\times$ & & \\
\hline Nerylacetone & Ketone & $\mathrm{C}_{13} \mathrm{H}_{22} \mathrm{O}$ & $\mathrm{b}$ & $\mathrm{p}$ & $\times$ & $\times$ & & & & & & $\times$ & \\
\hline 1-Dodecanol & Alcohol & $\mathrm{C}_{12} \mathrm{H}_{26} \mathrm{O}$ & $\mathrm{b}$ & $\mathrm{p}$ & & $\times$ & $\times$ & $\times$ & & & $\times$ & & \\
\hline Pentadecane & Alkane & $\mathrm{C}_{15} \mathrm{H}_{32}$ & $b, f$ & $a, i$ & & & & & & & $\times$ & $\times$ & \\
\hline Myristic acid & Carboxylic Acid & $\mathrm{C}_{14} \mathrm{H}_{28} \mathrm{O}_{2}$ & $b, f$ & $\mathrm{p}$ & $\times$ & & & & & & $\times$ & & \\
\hline Heneicosane & Alkane & $\mathrm{C}_{21} \mathrm{H}_{44}$ & $\mathrm{~b}$ & $\mathrm{p}$ & & & & & & & $\times$ & $\times$ & \\
\hline Docosane & Alkane & $\mathrm{C}_{22} \mathrm{H}_{46}$ & $b, f$ & $\mathrm{p}$ & & & & & & & $\times$ & $\times$ & \\
\hline
\end{tabular}

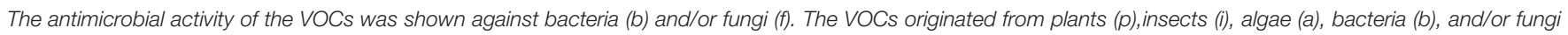
(f). Antimicrobial activities and origins are based on literature data (references in Supplementary Table 2). Detection of VOCs in the samples is indicated by " $\times$ ".

VOCs among sites. 1-Methoxy-2-propanol and 1-tridecene were detected in all nests. 2,6,11-Trimethyldodecane was detected in all web volatilomes. The other shared VOCs remain unknown.

\section{DISCUSSION}

The results of our study revealed the presence of numerous VOCs with antimicrobial function in the S. dumicola volatilomes. Overall, around $40 \%$ of the identified VOCs in the volatilomes of S. dumicola exhibit antimicrobial activity based on literature (references in Supplementary Table 2). In the present study, several pure VOCs, namely acetophenone, 1-tetradecene, 1-decanal, 2-decanone, and 1,3-benzothiazole, displayed antimicrobial activity against a range of spider and human pathogens. The suggested spider pathogen $B$. thuringiensis (Keiser et al., 2016) and the human pathogens S. aureus, E. coli, and C. albicans (Peterson, 2009; Canet et al., 2018) were significantly inhibited by most of the tested VOCs, indicating a possible protection of $S$. dumicola against bacteria (Grampositive and -negative) and yeasts. Our results are in line with several other studies that tested the antimicrobial activity of these compounds as pure compounds or extracts with concentrations between 0.55-43.8\% (Palic et al., 2002; Shi et al., 2010; Tayung et al., 2011; Li et al., 2012; Liu et al., 2012; Guleria et al., 2013;
Kazemi and Sharifi, 2017). For example, acetophenone and 2-decanone as pure compounds showed both antibacterial and -fungal activity (Rajabi et al., 2005; Sivakumar et al., 2008; Zheng et al., 2013; Jayakumar et al., 2020). The appearance of other antimicrobial VOCs was shown in other arthropod systems, for example in termites (Chen et al., 1998; Matsuura and Matsunaga, 2015), beetles (Gross et al., 2008), and ants (Wang et al., 2015). We found between 7 and 14 antimicrobial VOCs at each sampling site indicating likewise a high potential of the S. dumicola volatilomes in pathogen protection.

The origin of the VOCs in S. dumicola's volatilome appears to be diverse-in principle, the spiders themselves, symbiotic microorganisms, prey (and their microbiota), the plants in which the nests are located, and even passing or hostile animals could influence the volatilomes (Figure 5). Most of the VOCs with known antimicrobial activity identified in this study were previously reported from essential oils of plants, but some also from fungi, bacteria, algae, or even insects (Table 1). The lowest number of VOCs was found in the volatilomes of isolated spiders, whereas relatively more VOCs were detected in the nest and web volatilomes. Furthermore, the spider volatilomes only shared a small number of VOCs with the nest and web volatilomes, whereas the nest and web shared many common VOCs. Particularly the nest may provide a source for a diverse community of microbes as plant material and exoskeletons are 


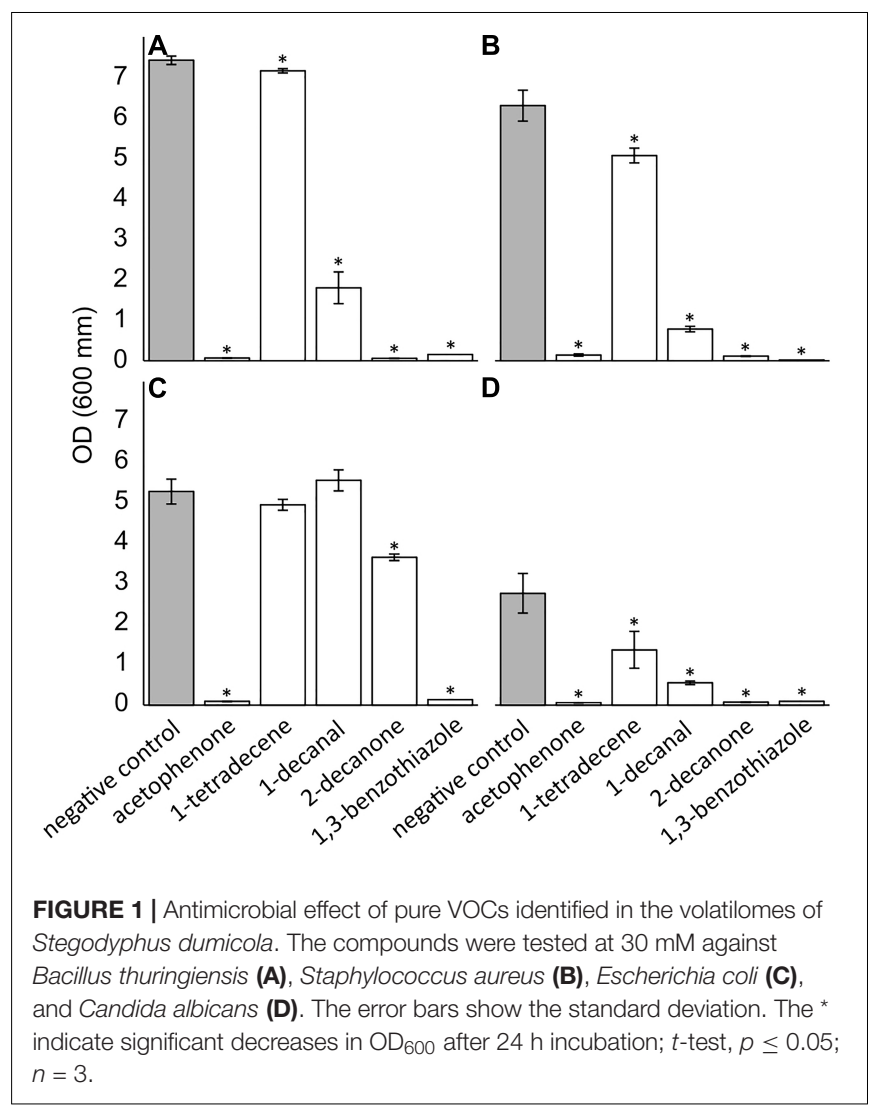

incorporated in the silk structure providing potential substrates for microbes. As the capture web is much more exposed to wind compared with the nest, we expected less VOCs in the web volatilomes than in the nest volatilomes, however, this was only the case in Windhoek.

A likely origin of VOCs is the $S$. dumicola nest microbiome. Although diverse and differing in composition and relative abundance from nest to nest, four bacterial genera (Curtobacterium, Modestobacter, Sphingomonas, and Massilia) and four fungal genera (Aureobasidium, Didymella, Alternaria, and Ascochyta) were found in all investigated $S$. dumicola nests and thus form a core nest microbiome (Nazipi et al., 2021). Currently, we cannot link specific VOCs to specific genera. However, the microbiome is the source of both soluble (Currie et al., 1999; Chouvenc et al., 2013; Mendes et al., 2013) and volatile (Musa Bandowe et al., 2009) antimicrobial compounds in other social arthropods, and some of the VOCs we identified in the spider nests are produced by microorganisms. For example, 2-decanone was found in the volatilomes of three Bacillus species and showed antifungal activity (Yuan et al., 2012; Zheng et al., 2013; Che et al., 2017; Jayakumar et al., 2020). Furthermore, 1-tetradecene was antimicrobial against numerous bacteria and fungi (Tayung et al., 2011). Another probable origin of the VOCs might be the arthropods themselves. A study identified pentadecane, an antimicrobial compound (Ozdemir et al., 2004; Hussain et al., 2017), in extracts of the head and gaster from argentine ants (Cavill and Houghton, 1974), and we identified the same compound in spider nests and webs in Stampriet. Pentadecane might have originated from dead prey or even hostile ants, even when we didn't observe the latter during field work. The spiders themselves may be a source of the volatilome. For example, it was shown that the cuticular profile of Stegodyphus lineatus contains several linear and branched alkanes (Grinsted et al., 2011) and myristic acid plays a role in sexual signaling in Tegenaria spp. (Trabalon et al., 1997). Most of the antimicrobial VOCs found in the volatilomes were identified in essential oils of plants, which contain volatile and non-volatile compounds, suggesting that the plants in which the spiders build their nests may influence the nest volatilome. For example, triterpenes extracted from Combretum imberbe and Acacia mellifera showed antibacterial activity (Angeh et al., 2007; Mutai et al., 2009a). The majority of the plant species in which the spider nests were located in, are known for their antibacterial, antifungal, and/or antiviral activity, even when detailed studies on the chemical compositions are lacking (Masoko et al., 2007, 2010; Peloewetse et al., 2008; Mutai et al., 2009b; Arbab et al., 2015; Lamola et al., 2017; Shikwambana and Mahlo, 2020). All in all, we found several VOCs in the nest, web, and spider volatilomes. The highest diversity was found in the nest and web samples even though the spiders are likely exposed to a mixture of all VOCs present in the spider nest ecosystem. It is likely that the volatilomes are produced communally by bacteria, fungi, plants, and the spiders, respectively, even though we have only little hints to concrete origins yet (Figure 5).

The PLS-DA analyses show clear differences between the three sampling sites for each of the analyzed volatilomes (nest, web, spider). The Euler plots support that finding, as the majority of the VOCs (approx. 94\%) were only found at one or two locations. There are various potential factors influencing the volatilomes. The nest microbiomes of $S$. dumicola were shown to differ significantly between different sampling sites, even though there is a core microbiome on genus level (Nazipi et al., 2021). A study investigating the spider microbiome of $S$. dumicola (endo- and exosymbionts) showed significant differences even between spiders from different nests from the same sampling site (Busck et al., 2020). Therefore, differences of the nest and spider microbiomes between the different geographic sites might contribute to the differences between the volatilomes found in the present study. The microbiome itself can be shaped by external factors like temperature, humidity, prey, soil, and plant species (Reese and Dunn, 2018). We found clear differences in temperature, humidity, and plant species between the sampling sites, which also goes in line with the differences between the volatilomes. The quantity and quality of the prey is also likely influenced by the location and climate (Majer et al., 2013, 2018). Furthermore, the plants themselves are a potential VOC source (Hammerbacher et al., 2019) and differed clearly between the sampling sites with a much higher plant density in Otavi compared to Windhoek and Stampriet (own observation). It was also shown that the production of essential oils by plants is decreased with increasing altitude (Haider et al., 2009; ElJalel et al., 2018) which is in line with our results. Thus, the lowest number of VOCs was found at the highest altitude (Windhoek). In contrast to the spider microbiome, it was shown 

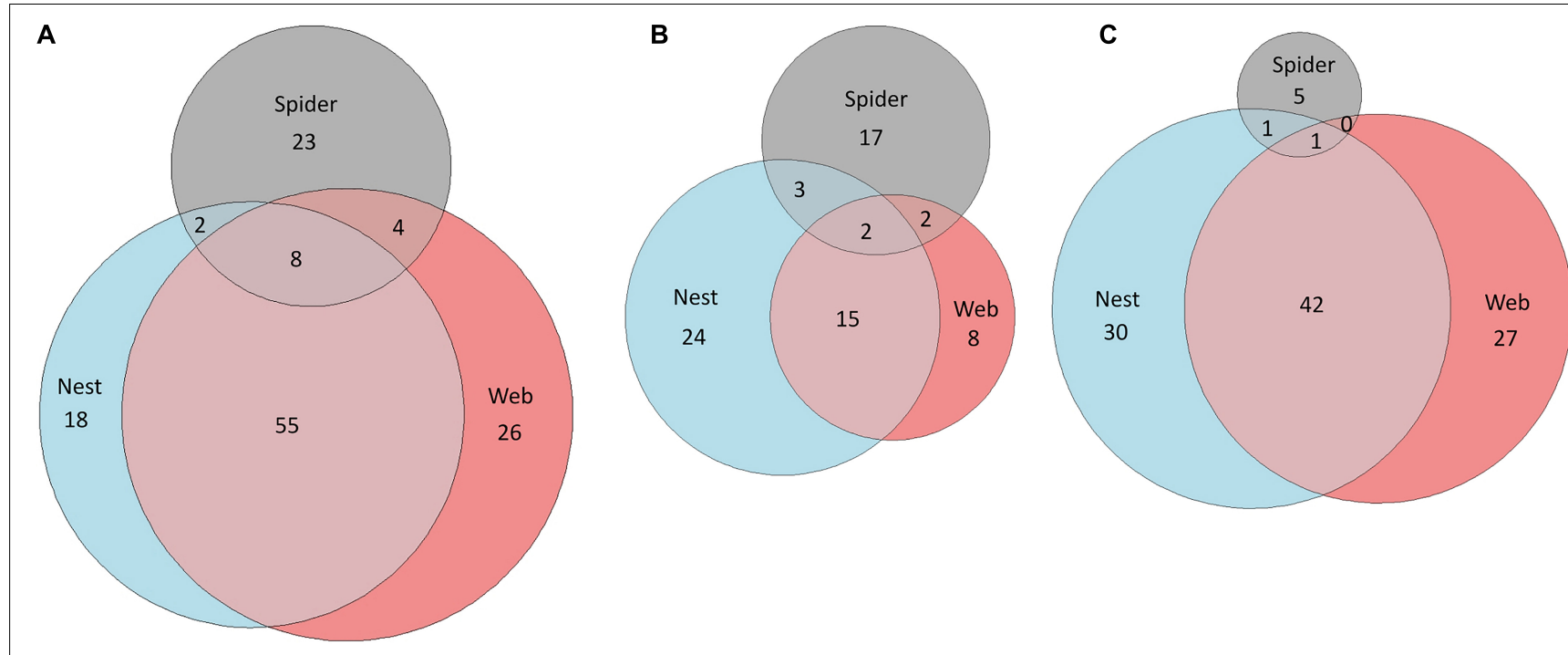

FIGURE 2 | Comparison of the nest, web, and spider volatilomes using Euler diagrams. The diagrams are based on all identified and unknown VOCs from Otavi (A), Windhoek (B), and Stampriet (C). The areas are proportional to the number of VOCs.
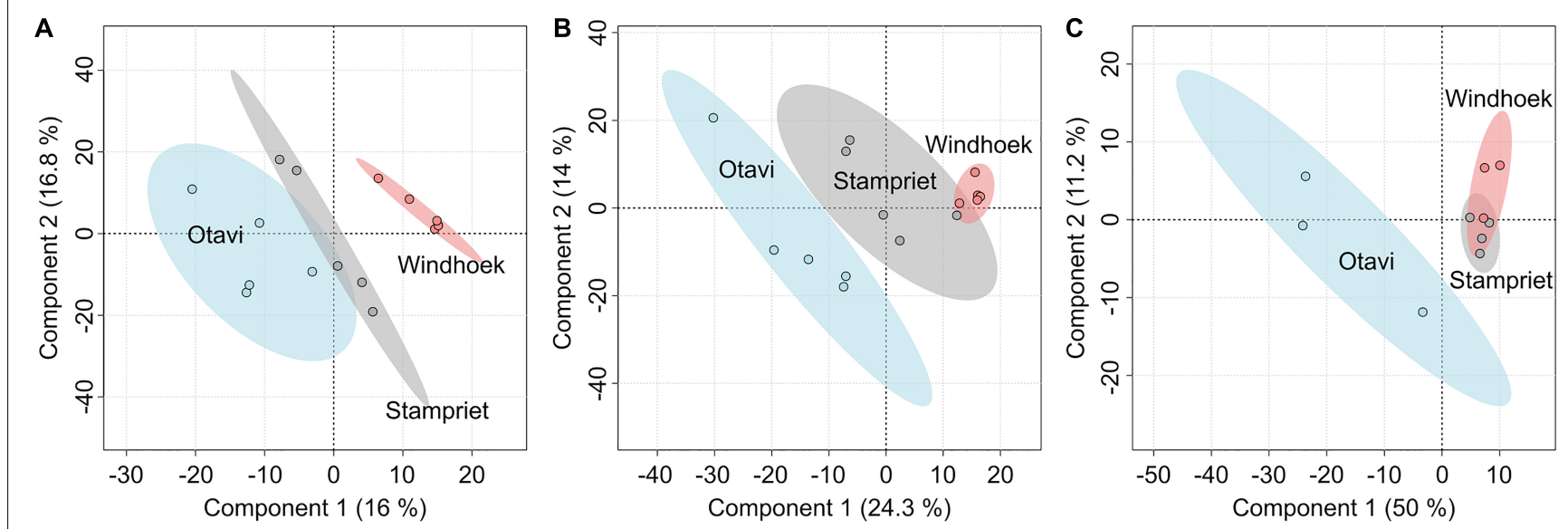

FIGURE 3 | Comparison of the volatilomes of the sampling sites Otavi, Windhoek, and Stampriet using partial least square discriminant analyses (PLS-DA). The diagrams are based on all identified and unknown VOCs of the nests (A), webs (B), and spiders (C). The semi-transparent colored areas show the 95\% confidence regions.

that S. dumicola shows little genetic differences between sampling sites (Settepani et al., 2017), which makes the spiders themselves very unlikely as an influencing factor for the differences between locations. Even though most of the VOCs were not shared between the sampling sites, some VOCs were present at all sites which suggests a site-independent "core volatilome" of S. dumicola. 12 VOCs were found in the nest volatilomes of all sampling sites and 11 VOCs in all web volatilomes. Two tentatively identified VOCs, namely 1-methoxy-2-propanol and 1-tridecene, were found in all nest volatilomes and 2,6,11trimethyldodecane and 1-tridecene in all web volatilomes. None of these compounds is known from other social insect or spider systems but 1-tridecene showed antibacterial activity (Kumar et al., 2011; Satmi and Hossain, 2016) and 1-dodecanol, a compound we found at all sampling sites in the nests or webs, is well known for its insecticidal (Tabanca et al., 2014) and antibacterial activity (Togashi et al., 2007; Vairappan et al., 2012). It is conceivable that this compound may protect $S$. dumicola against hostile insects like ants or wasps, but also against bacterial pathogens (Figure 5).

In conclusion, we found distinct differences between the sampling sites that can be explained with differences in the microbiomes, plant quality and quantity, prey quality, and physical parameters like temperature, humidity, and altitude. We lack information about the in situ concentrations of the VOCs, because it is technically impossible to combine minimal invasive, untargeted, and in situ volatilome analysis with quantitative conclusions. In soil systems it is known, that 

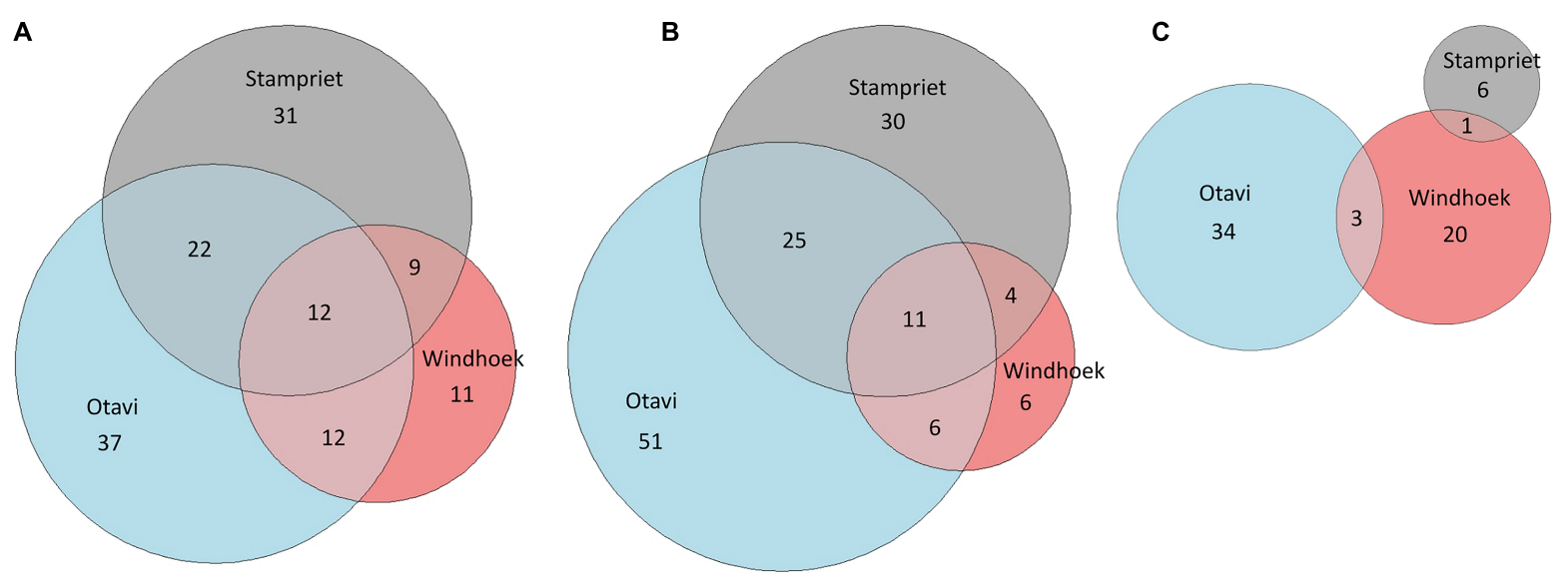

FIGURE 4 | Comparison of the volatilomes of the sampling sites Otavi, Windhoek, and Stampriet using Euler diagrams. The diagrams are based on all identified and unknown VOCs of the nests (A), webs (B), and spiders (C). The areas are proportional to the number of VOCs.

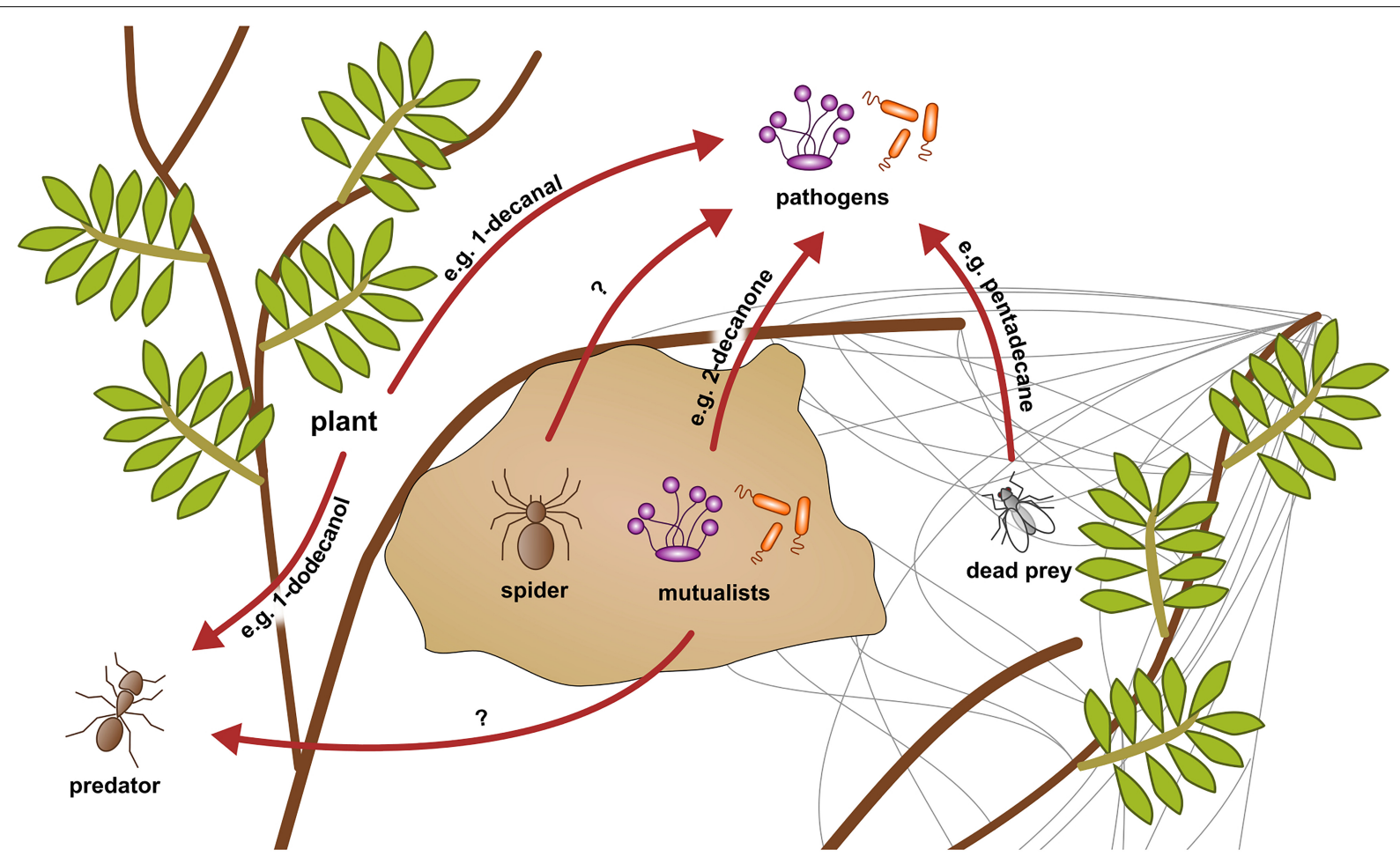

FIGURE 5 | Conceptual scheme of hypothetical VOC interactions in a social spider nest system. VOCs can be originated from the spiders themselves, their microbiome, dead prey, or the plants and inhibit pathogens and predators (red arrows). The example VoCs were found in the analyzed volatilomes of the present study. Their origin and influence are assumed based on literature.

aggregates creates micro-"incubators" influencing microbial life (Rillig et al., 2017). Similar phenomena may be possible in the spider nest ecosystem influencing the growth of certain microorganisms and the accumulation of antimicrobial VOCs. Nonetheless, we found hints for a core volatilome that may be important for the ecological success of $S$. dumicola. Overall, our study revealed that the volatilomes of $S$. dumicola contain numerous VOCs with antimicrobial potential that might play a key role in their pathogen defense. Apart from the tentatively identified VOCs the majority of $\sim 75 \%$ remains unknown. Therefore the $S$. dumicola system might contain more antimicrobial VOCs with the potential to protect the spiders and reveal novel classes of antimicrobial compounds. Next to antimicrobial protection VOCs can also play an important role in communication which should be addressed in further studies (Weisskopf et al., 2021). 


\section{DATA AVAILABILITY STATEMENT}

The original contributions presented in the study are included in the article/Supplementary Material, further inquiries can be directed to the corresponding author/s.

\section{AUTHOR CONTRIBUTIONS}

AL, AS, HZ, ML, PG, and TS designed the study. AL performed the volatilome trapping, GC/Q-TOF data analysis, and the antimicrobial testing, and wrote the manuscript with support from AS, PG, and TB. TS assisted in planning and realization of the fieldwork. HZ performed the GC/Q-TOF analysis. All authors reviewed the manuscript and approved the submitted version.

\section{FUNDING}

The study was supported by the Novo Nordisk Foundation Interdisciplinary Synergy Grant number NNF16OC0021110 and the Leibniz WissenschaftsCampus (ComBioCat) Grant number

\section{REFERENCES}

Angeh, J. E., Huang, X., Sattler, I., Swan, G. E., Dahse, H., Haertl, A., et al. (2007). Antimicrobial and anti-inflammatory activity of four known and one new triterpenoid from Combretum imberbe (Combretaceae). J. Ethnopharmacol. 110, 56-60. doi: 10.1016/j.jep.2006.09.002

Arbab, A. H., Parvez, M. K., Al-Dosari, M. S., Al-Rehaily, A. J., Al-Sohaibani, M., Zaroug, E. E., et al. (2015). Hepatoprotective and antiviral efficacy of Acacia mellifera leaves fractions against Hepatitis B Virus. Biomed. Res. Int. 2015:929131. doi: 10.1155/2015/929131

Aviles, L. (1997). "Causes and consequences of cooperation and permamentsociality in spiders," in The Evolution of Social Behavior in Insects and Arachnids, Vol. 2. eds J. C. Choe and B. J. Crespi (Cambridge: Cambridge University Press), 476-498. doi: 10.1017/CBO9780511721953.024

Bratburd, J. R., Arango, R. A., and Horn, H. A. (2020). Defensive symbioses in social insects can inform human health and agriculture. Front. Microbiol. 11:76. doi: $10.3389 /$ fmicb. 2020.00076

Busck, M. M., Settepani, V., Bechsgaard, J., Lund, M. B., Bilde, T., and Schramm, A. (2020). Microbiomes and specific symbionts of social spiders: compositional patterns in host species, populations, and nests. Front. Microbiol. 11:1845. doi: 10.3389/fmicb.2020.01845

Canet, M., Erdmenger, D., and Perez, W. (2018). ESKAPE pathogens resistance from blood cultures in a social security reference hospital in Guatemala. Int. J. Infect. Dis. 73:130. doi: 10.1016/j.ijid.2018.04.3710

Cavill, G., and Houghton, E. (1974). Volatile constituents of argentine ant, Iridomyrmex-humilis. J. Insect Physiol. 20, 2049-2059. doi: 10.1016/00221910(74)90112-7

Che, J., Liu, B., Liu, G., Chen, Q., and Lan, J. (2017). Volatile organic compounds produced by Lysinibacillus sp. FJAT-4748 possess antifungal activity against Colletotrichum acutatum. Biocontrol Sci. Technol. 27, 1349-1362. doi: 10.1080/ 09583157.2017.1397600

Chen, J., Henderson, G., Grimm, C. C., Lloyd, S. W., and Laine, R. A. (1998). Termites fumigate their nests with naphthalene. Nature 392, 558-559. doi: $10.1038 / 33305$

Chouvenc, T., Efstathion, C. A., Elliott, M. L., and Su, N.-Y. (2013). Extended disease resistance emerging from the faecal nest of a subterranean termite. Proc. R. Soc. B Biol. Sci. 280:20131885. doi: 10.1098/rspb.2013.1885

Currie, C. R., Scott, J. A., Summerbell, R. C., and Malloch, D. (1999). Fungusgrowing ants use antibiotic-producing bacteria to control garden parasites. Nature 398, 701-704. doi: 10.1038/19519
W10/2018. We would also like to thank the issued permissions to perform field work, permit no 1362/2017 was granted from the Ministry of Environment and Tourism in Windhoek, Namibia.

\section{ACKNOWLEDGMENTS}

We would like to thank Mette Marie Busck for great assistance during field work in Namibia, to Coleen Mannheimer for identifying the Namibian plants, and to John Irish for identifying plants and great support during field work in Namibia. We would also like to thank Sama Shiva for help with antimicrobial testing. This article is NIOO publication number 7244 .

\section{SUPPLEMENTARY MATERIAL}

The Supplementary Material for this article can be found online at: https://www.frontiersin.org/articles/10.3389/fmicb. 2021.700693/full\#supplementary-material

El-Jalel, L. F. A., Elkady, W. M., Gonaid, M. H., and El-Gareeb, K. A. (2018). Difference in chemical composition and antimicrobial activity of Thymus capitatus L. essential oil at different altitudes. Future J. Pharm. Sci. 4, 156-160. doi: 10.1016/j.fjps.2017.12.004

Fisher, K., West, M., Lomeli, A. M., Woodard, S. H., and Purcell, J. (2019). Are societies resilient? Challenges faced by social insects in a changing world. Insectes Sociaux 66, 5-13. doi: 10.1007/s00040-0180663-2

Graystock, P., and Hughes, W. O. H. (2011). Disease resistance in a weaver ant, Polyrhachis dives, and the role of antibiotic-producing glands. Behav. Ecol. Sociobiol. 65, 2319-2327. doi: 10.1007/s00265-011-1242-y

Grinsted, L., Bilde, T., and d'Ettorre, P. (2011). Cuticular hydrocarbons as potential kin recognition cues in a subsocial spider. Behav. Ecol. 22, 1187-1194. doi: 10.1093/beheco/arr105

Gross, J., Schumacher, K., Schmidtberg, H., and Vilcinskas, A. (2008). Protected by fumigants: beetle perfumes in antimicrobial defense. J. Chem. Ecol. 34, 179-188. doi: 10.1007/s10886-007-9416-9

Guleria, S., Tiku, A. K., Koul, A., Gupta, S., Singh, G., and Razdan, V. K. (2013). Antioxidant and antimicrobial properties of the essential oil and extracts of Zanthoxylum alatum grown in North-Western Himalaya. Sci. World J. 2013:790580. doi: 10.1155/2013/790580

Haider, F., Kumar, N., Banerjee, S., Naqvi, A. A., and Bagchi, G. D. (2009). Effect of altitude on the essential oil constituents of Artemisia roxburghiana Besser var. purpurascens (Jacq.) Hook. J. Essent. Oil Res. 21, 303-304. doi: 10.1080/ 10412905.2009.9700177

Hammerbacher, A., Coutinho, T. A., and Gershenzon, J. (2019). Roles of plant volatiles in defence against microbial pathogens and microbial exploitation of volatiles. Plant Cell Environ. 42, 2827-2843. doi: 10.1111/pce.13602

Henschel, J. R. (1998). Predation on social and solitary individuals of the spider Stegodyphus dumicola (Araneae. Eresidae). J. Arachnol. 26, 61-69.

Hölldobler, B., and Wilson, E. (1990). The Ants. Cambirdge: Harvard University Press.

Hudzicki, J. (2009). Kirby-Bauer Disk Diffusion Susceptibility Test Protocol. Available online at: http://www.asmscience.org/content/education/protocol/ protocol.3189 (accessed May 16, 2018

Hussain, A., Tian, M.-Y., and Wen, S.-Y. (2017). Exploring the caste-specific multilayer defense mechanism of formosan subterranean termites, Coptotermes formosanus Shiraki. Int. J. Mol. Sci. 18:2694. doi: 10.3390/ijms18122694

Jayakumar, V., Ramesh Sundar, A., and Viswanathan, R. (2020). Biocontrol of Colletotrichum falcatum with volatile metabolites produced by endophytic 
bacteria and profiling VOCs by headspace SPME coupled with GC-MS. Sugar Tech. 23, 94-107. doi: 10.1007/s12355-020-00891-2

Kazemi, M., and Sharifi, M. (2017). Composition, Antimicrobial and antioxidant activities of essential oil of Stachys kermanshahensis. Chem. Nat. Compd. 53, 767-769. doi: 10.1007/s10600-017-2116-y

Keiser, C. N., Shearer, T. A., DeMarco, A. E., Brittingham, H. A., Knutson, K. A., Kuo, C., et al. (2016). Cuticular bacteria appear detrimental to social spiders in mixed but not monoculture exposure. Curr. Zool. 62, 377-384. doi: 10.1093/cz/ zow015

Kumar, V., Bhatnagar, A. K., and Srivastava, J. N. (2011). Antibacterial activity of crude extracts of Spirulina platensis and its structural elucidation of bioactive compound. J. Med. Plants Res. 5, 7043-7048. doi: 10.5897/JMPR11.1175

Lamola, S. M., Dzoyem, J. P., Botha, F., and van Wyk, C. (2017). Antibacterial, free radical scavenging activity and cytotoxicity of acetone extracts of Grewia flava. Afr. Health Sci. 17, 790-796. doi: 10.4314/ahs.v1 $7 \mathrm{i} 3.22$

Li, M., Han, G., Chen, H., Yu, J., and Zhang, Y. (2012). Chemical compounds and antimicrobial activity of volatile oils from bast and fibers of Apocynum venetum. Fibers Polym. 13, 322-328. doi: 10.1007/s12221-012-0322-6

Liu, K., Chen, Q., Liu, Y., Zhou, X., and Wang, X. (2012). Isolation and biological activities of decanal, linalool, valencene, and octanal from sweet orange oil. J. Food Sci. 77, C1156-C1161. doi: 10.1111/j.1750-3841.2012.02924.x

Lubin, Y., and Bilde, T. (2007). The evolution of sociality in spiders. Adv. Stud. Behav. 37, 83-145. doi: 10.1016/S0065-3454(07)37003-4

Majer, M., Holm, C., Lubin, Y., and Bilde, T. (2018). Cooperative foraging expands dietary niche but does not offset intra-group competition for resources in social spiders. Sci. Rep. 8:11828. doi: 10.1038/s41598-018-30199-x

Majer, M., Svenning, J.-C., and Bilde, T. (2013). Habitat productivity constrains the distribution of social spiders across continents - case study of the genus Stegodyphus. Front. Zool. 10:9. doi: 10.1186/1742-9994-10-9

Masoko, P., Picard, J., and Eloff, J. N. (2007). The antifungal activity of twentyfour southern African Combretum species (Combretaceae). South Afr. J. Bot. 73, 173-183. doi: 10.1016/j.sajb.2006.09.010

Masoko, P., Picard, J., Howard, R. L., Mampuru, L. J., and Eloff, J. N. (2010). In vivo antifungal effect of Combretum and Terminalia species extracts on cutaneous wound healing in immunosuppressed rats. Pharm. Biol. 48, 621-632. doi: $10.3109 / 13880200903229080$

Matsuura, K., and Matsunaga, T. (2015). Antifungal activity of a termite queen pheromone against egg-mimicking termite ball fungi. Ecol. Res. 30, 93-100. doi: 10.1007/s11284-014-1213-7

Mendes, T. D., Borges, W. S., Rodrigues, A., Solomon, S. E., Vieira, P. C., Duarte, M. C. T., et al. (2013). Anti-Candida properties of urauchimycins from actinobacteria associated with Trachymyrmex ants. Biomed. Res. Int. 2013:835081. doi: 10.1155/2013/835081

Montenegro, I., Said, B., Godoy, P., Besoain, X., Parra, C., Diaz, K., et al. (2020). Antifungal activity of essential oil and main components from mentha pulegium growing wild on the chilean central coast. Agronomy 10:254. doi: 10.3390/agronomy 10020254

Müller, C. B., and Schmid-Hempel, P. (1993). Exploitation of cold temperature as defence against parasitoids in bumblebees. Nature 363, 65-67. doi: 10.1038/ $363065 \mathrm{a} 0$

Musa Bandowe, B. A., Rückamp, D., Bragança, M. A. L., Laabs, V., Amelung, W., Martius, C., et al. (2009). Naphthalene production by microorganisms associated with termites: evidence from a microcosm experiment. Soil Biol. Biochem. 41, 630-639. doi: 10.1016/j.soilbio.2008.12.029

Mutai, C., Bii, C., Rukunga, G., Ondicho, J., Mwitari, P., Abatis, D., et al. (2009a). Antimicrobial activity of pentacyclic triterpenes isolated from Acacia mellifera. Afr. J. Tradit. Complement. Altern. Med. 6, 42-48.

Mutai, C., Bii, C., Vagias, C., Abatis, D., and Roussis, V. (2009b). Antimicrobial activity of Acacia mellifera extracts and lupane triterpenes. J. Ethnopharmacol. 123, 143-148. doi: 10.1016/j.jep.2009.02.007

Nazipi, S., Lorenzen Elberg, C., Busck, M. M., Lund, M. B., Bilde, T., and Schramm, A. (2021). The bacterial and fungal nest microbiomes in populations of the social spider Stegodyphus dumicola. Syst. Appl. Microbiol 44:126222.

Okla, M. K., Alamri, S. A., Salem, M. Z. M., Ali, H. M., Behiry, S., Nasser, R. A., et al. (2019). Yield, phytochemical constituents, and antibacterial activity of essential oils from the leaves/twigs, branches, branch wood, and branch bark of sour orange (Citrus aurantium L.). Processes 7:363. doi: 10.3390/pr7060363
Ossowicki, A., Jafra, S., and Garbeva, P. (2017). The antimicrobial volatile power of the rhizospheric isolate Pseudomonas donghuensis P482. PLoS One 12:e0174362. doi: 10.1371/journal.pone.0174362

Ozdemir, G., Karabay, N. U., Dalay, M. C., and Pazarbasi, B. (2004). Antibacterial activity of volatile component and various extracts of Spirulina platensis. Phytother. Res. 18, 754-757. doi: 10.1002/ptr.1541

Palic, R., Stojanovic, G., Alagic, S., Nikolic, M., and Lepojevic, Z. (2002). Chemical composition and antimicrobial activity of the essential oil and $\mathrm{CO} 2$ extracts of the oriental tobacco, Prilep. Flavour Fragr. J. 17, 323-326. doi: 10.1002/ffj. 1084

Pandey, A., and Banerjee, D. (2014). Daldinia bambusicola Ch4/11 an endophytic fungus producing volatile organic compounds having antimicrobial and olio chemical potential. J. Adv. Microbiol. 6, 330-337.

Pavithra, P. S., Sreevidya, N., and Verma, R. S. (2009). Antibacterial activity and chemical composition of essential oil of Pamburus missionis. J. Ethnopharmacol. 124, 151-153. doi: 10.1016/j.jep.2009.04.016

Peloewetse, E., Thebe, M. M., Ngila, J. C., and Ekosse, G. E. (2008). Inhibition of growth of some phytopathogenic and mycotoxigenic fungi by aqueous extracts of Combretum imberbe (Wawra) wood. Afr. J. Biotechnol. 7, 2934-2939. doi: 10.4314/ajb.v7i16.59204

Peterson, L. R. (2009). Bad bugs, no drugs: no ESCAPE revisited. Clin. Infect. Dis. 49, 992-993. doi: 10.1086/605539

Pluskal, T., Castillo, S., Villar-Briones, A., and Orešič, M. (2010). MZmine 2: modular framework for processing, visualizing, and analyzing mass spectrometry-based molecular profile data. BMC Bioinformatics 11:395. doi: 10.1186/1471-2105-11-395

Rajabi, L., Courreges, C., Montoya, J., Aguilera, R. J., and Primm, T. P. (2005). Acetophenones with selective antimycobacterial activity. Lett. Appl. Microbiol. 40, 212-217. doi: 10.1111/j.1472-765X.2005.01657.x

Reese, A. T., and Dunn, R. R. (2018). Drivers of microbiome biodiversity: a review of general rules, feces, and ignorance. mBio 9:e01294-18. doi: 10.1128/mBio. 01294- 18

Rillig, M. C., Muller, L. A., and Lehmann, A. (2017). Soil aggregates as massively concurrent evolutionary incubators. ISME J. 11, 1943-1948. doi: 10.1038/ismej. 2017.56

Rowan, D. D. (2011). Volatile metabolites. Metabolites 1, 41-63. doi: 10.3390/ metabo1010041

Roy, S., Rao, K., Bhuvaneswari, Ch, Giri, A., and Mangamoori, L. N. (2009). Phytochemical analysis of Andrographis paniculata extract and its antimicrobial activity. World J. Microbiol. Biotechnol 26, 85-91. doi: 10.1007/s11274-0090146-8

Satmi, F. R. S., and Hossain, M. A. (2016). In vitro antimicrobial potential of crude extracts and chemical compositions of essential oils of leaves of Mentha piperita L native to the Sultanate of Oman. Pac. Sci. Rev. Nat. Sci. Eng. 18, 103-106. doi: 10.1016/j.psra.2016.09.005

Schmidt, R., Cordovez, V., de Boer, W., Raaijmakers, J., and Garbeva, P. (2015a). Volatile affairs in microbial interactions. ISME J. 9, 2329-2335. doi: 10.1038/ ismej. 2015.42

Schmidt, R., Etalo, D. W., de Jager, V., Gerards, S., Zweers, H., de Boer, W., et al. (2015b). Microbial small talk: volatiles in fungal-bacterial interactions. Front. Microbiol. 6:1495. doi: 10.3389/fmicb.2015.01495

Schulz-Bohm, K., Martin-Sanchez, L., and Garbeva, P. (2017). Microbial volatiles: small molecules with an important role in intra- and inter-kingdom interactions. Front. Microbiol. 8:2484. doi: 10.3389/fmicb.2017.02484

Seibt, U., and Wickler, W. (1990). The protective function of the compact silk nest of social Stegodyphus spiders (Araneae, Eresidae). Oecologia 82, 317-321. doi: 10.1007/BF00317477

Settepani, V., Bechsgaard, J., and Bilde, T. (2014). Low genetic diversity and strong but shallow population differentiation suggests genetic homogenization by metapopulation dynamics in a social spider. J. Evol. Biol. 27, 2850-2855. doi: $10.1111 /$ jeb. 12520

Settepani, V., Bechsgaard, J., and Bilde, T. (2016). Phylogenetic analysis suggests that sociality is associated with reduced effectiveness of selection. Ecol. Evol. 6, 469-477. doi: 10.1002/ece3.1886

Settepani, V., Schou, M. F., Greve, M., Grinsted, L., Bechsgaard, J., and Bilde, T. (2017). Evolution of sociality in spiders leads to depleted genomic diversity at both population and species levels. Mol. Ecol. 26, 4197-4210. 
Shi, B., Liu, W., Wei, S., and Wu, W. (2010). Chemical composition, antibacterial and antioxidant activity of the essential oil of Bupleurum longiradiatum. Nat. Prod. Commun. 5, 1139-1142. doi: 10.1177/1934578X1000500734

Shikwambana, N., and Mahlo, S. M. (2020). A survey of antifungal activity of selected south African plant species used for the treatment of skin infections. Nat. Prod. Commun. 15, 1-10. doi: 10.1177/1934578X20923181

Sinek, K., Iskender, N. Y., Yayli, B., Karaoglu, S. A., and Yayli, N. (2012). Antimicrobial activity and chemical composition of the essential oil from Campanula glomerata L. Subsp Hispida (Witasek) Hayek. Asian J. Chem. 24, 1931-1934.

Sivakumar, P. M., Sheshayan, G., and Doble, M. (2008). Experimental and QSAR of acetophenones as antibacterial agents. Chem. Biol. Drug Des. 72, 303-313.

Tabanca, N., Gao, Z., Demirci, B., Techen, N., Wedge, D. E., Ali, A., et al. (2014). Molecular and phytochemical investigation of Angelica dahurica and Angelica pubescentis essential oils and their biological activity against Aedes aegypti, Stephanitis pyrioides, and Colletotrichum species. J. Agric. Food Chem. 62, 8848-8857. doi: 10.1021/jf5024752

Tariq, S., Wani, S., Rasool, W., Shafi, K., Bhat, M. A., Prabhakar, A., et al. (2019). A comprehensive review of the antibacterial, antifungal and antiviral potential of essential oils and their chemical constituents against drug-resistant microbial pathogens. Microb. Pathog. 134:103580. doi: 10.1016/j.micpath.2019.103580

Tayung, K., Barik, B., Jha, D., and Deka, D. (2011). Identification and characterization of antimicrobial metabolite from an endophytic fungus, Fusarium solani isolated from bark of Himalayan yew. Mycosphere 2, 203-213.

Togashi, N., Shiraishi, A., Nishizaka, M., Matsuoka, K., Endo, K., Hamashima, H., et al. (2007). Antibacterial activity of long-chain fatty alcohols against Staphylococcus aureus. Molecules 12, 139-148. doi: 10.3390/12020139

Trabalon, M., Bagnères, A. G., and Roland, C. (1997). Contact sex signals in two sympatric spider species, Tegenaria domestica and Tegenaria pagana. J. Chem. Ecol. 23, 747-758. doi: 10.1023/B:JOEC.0000006408.60663.db

Tyc, O., Zweers, H., de Boer, W., and Garbeva, P. (2015). Volatiles in inter-specific bacterial interactions. Front. Microbiol. 6:1412. doi: 10.3389/fmicb.2015.01412

Vairappan, C. S., Nagappan, T., and Palaniveloo, K. (2012). Essential oil composition, cytotoxic and antibacterial activities of five Etlingera species from Borneo. Nat. Prod. Commun. 7, 239-249. doi: 10.1177/1934578X1200700233

Wang, L., Elliott, B., Jin, X., Zeng, L., and Chen, J. (2015). Antimicrobial properties of nest volatiles in red imported fire ants, Solenopsis invicta (hymenoptera: formicidae). Sci. Nat. 102:66. doi: 10.1007/s00114-015-1316-1

Weisskopf, L., Schulz, S., and Garbeva, P. (2021). Microbial volatile organic compounds in intra-kingdom and inter-kingdom interactions. Nat. Rev. Microbiol. 19, 391-404. doi: 10.1038/s41579-020-00508-1
Wilson, E. O. (1987). Causes of ecological success: the case of the ants. J. Anim. Ecol. 56, 1-9. doi: 10.2307/4795

Wood, W. F., and Szewczak, J. M. (2007). Volatile antimicrobial compounds in the pelage of the Mexican free-tailed bat, Tadarida brasiliensis mexicana. Biochem. Syst. Ecol. 35, 566-568. doi: 10.1016/j.bse.2007.04.002

Xia, J., and Wishart, D. S. (2011). Web-based inference of biological patterns, functions and pathways from metabolomic data using MetaboAnalyst. Nat. Protoc. 6, 743-760. doi: 10.1038/nprot.2011.319

Yuan, J., Raza, W., Shen, Q., and Huang, Q. (2012). Antifungal activity of Bacillus amyloliquefaciens NJN-6 volatile compounds against Fusarium oxysporum f. sp. cubense. Appl. Environ. Microbiol. 78, 5942-5944. doi: 10.1128/AEM.01357-12

Zellagui, A., Gherraf, N., and Rhouati, S. (2012). Chemical composition and antibacterial activity of the essential oils of Ferula vesceritensis Coss et Dur. leaves, endemic in Algeria. Org. Med. Chem. Lett. 2:31. doi: 10.1186/2191-28582-31

Zheng, M., Shi, J., Shi, J., Wang, Q., and Li, Y. (2013). Antimicrobial effects of volatiles produced by two antagonistic Bacillus strains on the anthracnose pathogen in postharvest mangos. Biol. Control 65, 200-206. doi: 10.1016/j. biocontrol.2013.02.004

Zhu, Q., Jiang, M.-L., Shao, F., Ma, G.-Q., Shi, Q., and Liu, R.-H. (2020). Chemical composition and antimicrobial activity of the essential oil from Euphorbia helioscopia L. Nat. Prod. Commun. 15, 1-6. doi: 10.1177/1934578X2095 3249

Conflict of Interest: The authors declare that the research was conducted in the absence of any commercial or financial relationships that could be construed as a potential conflict of interest.

Publisher's Note: All claims expressed in this article are solely those of the authors and do not necessarily represent those of their affiliated organizations, or those of the publisher, the editors and the reviewers. Any product that may be evaluated in this article, or claim that may be made by its manufacturer, is not guaranteed or endorsed by the publisher.

Copyright (C) 2021 Lammers, Zweers, Sandfeld, Bilde, Garbeva, Schramm and Lalk. This is an open-access article distributed under the terms of the Creative Commons Attribution License (CC BY). The use, distribution or reproduction in other forums is permitted, provided the original author(s) and the copyright owner(s) are credited and that the original publication in this journal is cited, in accordance with accepted academic practice. No use, distribution or reproduction is permitted which does not comply with these terms. 